\title{
How Much Do Older Adults Living Alone in Rural South Korea Know About Dementia?
}

\author{
Mi Sook Kim ${ }^{1}$, Dong-Soo Shin ${ }^{2,3}$, Yong-jun Choi ${ }^{4,5}$, Jin Soon Kim ${ }^{6}$ \\ ${ }^{1}$ Department of Nursing, Kaya University, Gimhae, Korea; ${ }^{2}$ Division of Nursing, Hallym University, Chucheon, Korea; ${ }^{3}$ Research Institute of Nursing \\ Science, Hallym University, Chucheon, Korea; ${ }^{4}$ Department of Social and Preventive Medicine, Hallym University College of Medicine, Chucheon, \\ Korea; ${ }^{5}$ Health Services Research Center, Hallym University, Chucheon, Korea; ${ }^{6}$ Danglim Primary Health Care Post, Chuncheon, Korea
}

Objectives: This study aimed to examine the level of dementia knowledge of older Korean adults living alone in rural areas and to identify related factors.

Methods: A cross-sectional descriptive design was applied. The participants were 231 older adults living alone who were recruited from 12 of the 13 primary health care posts in the rural area of Chuncheon. Participants' level of dementia knowledge was assessed using the Dementia Knowledge Scale. Data were analyzed using descriptive statistics, and the $t$-test, analysis of variance, chi-square test, and Mann-Whitney test were applied.

Results: Participants' mean age was $77.3 \pm 5.4$ years, and women comprised $79.7 \%$ of the sample. Over half of the participants (61.9\%) had no formal education, and all the participants were enrolled in Medical Aid. The participants' average percentage of correct answers was $61.6 \%$. The highest rate (94.4\%) was for the item "Dementia can change one's personal character." The item with the lowest proportion of correct answers was "Dementia is not treatable" (23.4\%). Dementia knowledge was significantly associated with age, education, health coverage, source of living expenses, and dementia risk.

Conclusions: Dementia knowledge among Korean rural older adults living alone was relatively low. Participants' misconceptions about symptoms and treatment could hinder them from seeking early treatment. The results of this study suggest the need for active outreach and health care delivery for rural older adults living alone in South Korea.

Key words: Aged, Dementia, Knowledge, Rural health, Korea

\section{INTRODUCTION}

Dementia has emerged as one of the most important health challenges throughout the world [1], and South Korea (hereafter Korea) is no exception. In Korea, $9.2 \%$ of people aged 65

Received: May 30, 2017 Accepted: June 8, 2018

Corresponding author: Yong-jun Choi, MD, PhD

Department of Social and Preventive Medicine, Hallym University

College of Medicine, 1 Hallymdaehak-gil, Chuncheon 24252, Korea

E-mail: ychoi@hallym.ac.kr

This is an Open Access article distributed under the terms of the Creative Commons Attribution Non-Commercial License (http://creativecommons.org/licenses/by$\mathrm{nc} / 4.0 / /$ which permits unrestricted non-commercial use, distribution, and reproduction in any medium, provided the original work is properly cited. and over were estimated to have dementia in 2012 [2], and the prevalence is expected to increase to $15.6 \%$ by 2050 [2]. The prevalence of mild cognitive impairment, a risk factor of dementia [3], among adults aged 65 and over was estimated to be $27.5 \%$ in 2012 [2], and there were more people in this age group with mild cognitive impairment in rural areas (30.7\%) than in urban areas (20.5\%) [2]. In addition, the economic costs of dementia have enormously increased in Korea. Suh et al. [4] estimated its total annual cost to be over USD 2.4 billion in 2002, and a recent study [5] forecast that the annual cost of dementia would reach a total of USD 37.5 billion by 2050 .

Dementia should receive more attention as a health issue for older adults in the rural areas of Korea, especially for those 
living alone. First, the proportion of individuals over 65 of age has increased more rapidly in rural areas than in urban areas. While the proportion of people aged 65 and over in urban areas increased from $5.5 \%$ in 2000 to $9.2 \%$ in 2010, the proportion of those living in rural areas rose from 14.7 to $20.7 \%$ over the same period [6]. Second, rural older adults are in poorer health and have more difficulties accessing health care than their urban counterparts. For example, the self-rated health of rural older adults was found to be poorer than that of their urban counterparts [7], and rural older adults were less physically active than their urban counterparts $[7,8]$. These are risk factors for dementia [9-13]. In addition, older adults in rural areas have been found to use fewer health care than those in urban areas due to the concentration of health care resources in urban areas [7]. There is a misconception that dementia is part of the normal aging process [14], and as a result, rural older adults may have difficulty accessing treatment for early-stage dementia. Moreover, more older adults live alone in rural areas (33.5\%) than in urban areas (22.7\%) [6]. Older adults living alone tend to experience faster cognitive decline than those living with others, including family members, due to a monotonous life pattern and lack of environmental stimulation [15-18].

Currently, early detection, intervention, and risk reduction are known as the best ways to lower the dementia burden [19]. Therefore, individuals need to be informed about the progress and management of dementia, because older adults with such knowledge can be actively engaged in preventive behaviors [20]. However, little evidence exists about how much older adults living alone in rural areas, an especially vulnerable group, know about dementia. Therefore, this study aimed to examine the level of dementia knowledge of older Korean adults living alone in rural areas and to identify related factors.

\section{METHODS}

\section{Participants and Procedures}

After obtaining institutional review board approval, participants were recruited from 12 of the 13 primary health care posts in the rural area of the city of Chuncheon. The study's purpose and process were announced at the primary health care posts. Of 393 registered older adults living alone, 231 agreed to participate in this study (response rate, 58.8\%). Written consent was obtained, and small incentives, such as snacks and beverages, were given. Data were collected by $12 \mathrm{com}$ - munity health practitioners who were trained to assess older residents. Data were gathered during January 2014.

\section{Measures}

Information on study participants' characteristics - gender, age, educational level, type of health coverage, source of living expenses, number of chronic diseases, self-rated health, and alcohol consumption - was collected using a questionnaire. Regarding types of health coverage, Medical Aid is a public assistance program that enables the poor to have access to health care at little or no charge. Type 1 Medical Aid beneficiaries are generally poorer than their type 2 counterparts.

Participants' level of dementia knowledge was assessed by the Dementia Knowledge Scale (DKS), which was developed by the research team of the Nationwide Prevalence Study of Dementia in Korean elders [2]. It is a 15-item questionnaire with yes/no responses. Its items are composed of questions about causes (items 1, 2, 4, 5, 7), prevalence and the health system (items $3,6,15$ ), symptoms and diagnosis (items 8-11), and prevention and treatment (items 12-14) of dementia. Scores reflect the number of items answered correctly. A higher score indicates a higher level of dementia knowledge.

Level of cognitive function was assessed by the Korean version of the Mini-Mental State Examination for Dementia Screening (MMSE-DS) [21,22], a culturally modified MMSE developed by Folstein et al. [23]. It has been widely used in primary health care in Korea $[2,21,24]$. An MMSE-DS score of 23 or lower suggests mild cognitive decline, and it is also used to identify people at-risk for dementia by considering gender, age, and education $[21,22]$.

\section{Data Analysis}

SPSS version 22.0 (IBM Corp., Armonk, NY, USA) was used to analyze the data. Descriptive statistics were used to show the basic characteristics of participants and levels of dementia knowledge by gender. The $t$-test, analysis of variance, chisquare test, and Mann-Whitney test were applied to identify differences in dementia knowledge by participants' characteristics and dementia risk. The outcome measure was the DKS score. A statistical significance level of $p<0.05$ for 2 -sided tests was used.

\section{Ethics Approval}

The study protocol was approved by the institutional review board of Hallym University (HR-2013-61). 


\section{RESULTS}

\section{Participants' Characteristics}

Participants' characteristics are presented in Table 1. Their mean age was $77.3 \pm 5.4$ years, and women comprised $79.7 \%$ of the participants. Over half of them (61.9\%) had no formal education, and all the participants were enrolled in Medical Aid. Over one-third of the participants (34.6\%) lived on income from their work, followed by financial support from their children (32.0\%) and public assistance (18.6\%). Only $9.1 \%$ of the study participants were free from chronic illness, while $21.2 \%$ of them suffered from more than 3 chronic diseases. Those who rated their health status as bad or very bad comprised $20.8 \%$ of the participants. Roughly one-third of the participants drank alcohol more than once a week. The mean score on the MMSE-DS was $23.2 \pm 3.8$, and those who scored 23 or lower comprised $51.5 \%$ of the sample. The high-risk group was identified based on gender, age, and education, as well as the MMSE-DS score, and $6.9 \%$ of the participants were deemed to be at-risk for dementia, requiring further examination and treatment.

\section{Dementia Knowledge and Item Responses}

Table 2 summarizes the rates of correct answers for study participants. The average percentage of correct answers was $61.6 \%$. Among the 4 categories of dementia knowledge, treatment and prevention showed the highest rate of correct answers (69.4\%) followed by symptoms and diagnosis (66.9\%), causes $(62.8 \%)$, and prevalence and the health system (44.7\%). Three items showed rates of correct answers over $90 \%$. The highest rate was $94.4 \%$ for “Dementia can change one's personal character." The item "Regular exercise can prevent dementia" had a correct answer rate of $93.5 \%$. The third-highest rate (91.3\%) was for the item "Early treatment can delay dementia's progress."

The item with the lowest proportion of correct answers was "Dementia is not treatable" (23.4\%). The item with the second lowest correct answer rate was related to the prevalence of dementia, as $71.0 \%$ of the participants mistakenly thought that dementia occurs in only 1 out of 100 people. The third lowest rate (30.3\%) was for the item "When someone has intact memories of long-ago events, s/he doesn't get dementia." Other items that less than half of the participants answered correctly were: "If parents have dementia, their children will have it" (40.3\%), "All people with dementia can be registered
Table 1. Characteristics of study participants $(n=231)$

\begin{tabular}{|c|c|}
\hline Characteristics & n (\%) \\
\hline \multicolumn{2}{|l|}{ Gender } \\
\hline Women & $184(79.7)$ \\
\hline Men & $47(20.3)$ \\
\hline \multicolumn{2}{|l|}{ Age (y) } \\
\hline Mean \pm SD & $77.3 \pm 5.4$ \\
\hline $65-69$ & 18 (7.8) \\
\hline $70-74$ & $49(21.2)$ \\
\hline $75-79$ & $90(39.0)$ \\
\hline $80-84$ & $50(21.6)$ \\
\hline$\geq 85$ & $24(10.4)$ \\
\hline \multicolumn{2}{|l|}{ Education } \\
\hline None & $143(61.9)$ \\
\hline Elementary & $58(25.1)$ \\
\hline$\geq$ Middle school & $30(13.0)$ \\
\hline \multicolumn{2}{|l|}{ Health coverage (Medical Aid) } \\
\hline Type 1 & 38 (16.5) \\
\hline Type 2 & 193 (83.5) \\
\hline \multicolumn{2}{|l|}{ Source of living expenses } \\
\hline Working & $80(34.6)$ \\
\hline Support from children & $74(32.0)$ \\
\hline Public assistance & $43(18.6)$ \\
\hline Others & $34(14.7)$ \\
\hline \multicolumn{2}{|l|}{ No. of chronic diseases } \\
\hline 0 & $21(9.1)$ \\
\hline 1 & $80(34.6)$ \\
\hline 2 & $81(35.1)$ \\
\hline$\geq 3$ & 49 (21.2) \\
\hline \multicolumn{2}{|l|}{ Self-rated health } \\
\hline Very good & $10(4.3)$ \\
\hline Good & 72 (31.2) \\
\hline Fair & $101(43.7)$ \\
\hline Bad & 43 (18.6) \\
\hline Very bad & $5(2.2)$ \\
\hline \multicolumn{2}{|l|}{ Drinks alcohol ( $\geq 1 /$ wk) } \\
\hline Yes & 69 (29.9) \\
\hline No & $162(70.1)$ \\
\hline MMSE-DS (mean $\pm S D$, score) & $23.2 \pm 3.8$ \\
\hline $0-23$ & $119(51.5)$ \\
\hline$\geq 24$ & $112(48.5)$ \\
\hline \multicolumn{2}{|l|}{ Dementia risk by MMSE-DS } \\
\hline At-risk & $16(6.9)$ \\
\hline Dementia Knowledge Scale (mean \pm SD) & $9.2 \pm 2.0$ \\
\hline
\end{tabular}

SD, standard deviation; MMSE-DS, Mini-Mental State Examination for Dementia Screening.

as people with a disability" (41.6\%), and "People get dementia as they age" (49.8\%).

There were differences in the mean DKS scores between men 
Table 2. Correct answers to Dementia Knowledge Scale items

\begin{tabular}{|c|c|c|c|c|c|c|}
\hline Category & Item & $\begin{array}{l}\text { Correct } \\
\text { answer }\end{array}$ & $\begin{array}{c}\text { Total } \\
(\mathrm{n}=231)\end{array}$ & $\begin{array}{c}\text { Men } \\
(n=47)\end{array}$ & $\begin{array}{l}\text { Women } \\
(\mathrm{n}=184)\end{array}$ & p-value ${ }^{1}$ \\
\hline \multirow[t]{6}{*}{ Causes } & 1. People get dementia as they age & No & $115(49.8)$ & $26(55.3)$ & $89(48.4)$ & 0.39 \\
\hline & 2. Dementia is a disease of the brain & Yes & $198(85.7)$ & $37(78.7)$ & $161(87.5)$ & 0.12 \\
\hline & 4. Dementia can occur due to stroke & Yes & $150(64.9)$ & $33(70.2)$ & $117(63.6)$ & 0.40 \\
\hline & 5. Heavy drinking increases a person's chance of getting dementia & Yes & $169(73.2)$ & $33(70.2)$ & $136(73.9)$ & 0.61 \\
\hline & 7. If parents have dementia, their children will have it & No & $93(40.3)$ & $25(53.2)$ & $68(37.0)$ & 0.04 \\
\hline & Average \% correct & & (62.8) & (65.5) & (62.1) & \\
\hline \multirow{4}{*}{$\begin{array}{l}\text { Prevalence and the } \\
\text { health system }\end{array}$} & 3. Dementia occurs more in men than in women & Yes & $147(63.6)$ & $20(42.6)$ & $127(69.0)$ & 0.001 \\
\hline & 6. 1 out of 100 older adults has dementia & No & $67(29.0)$ & $21(44.7)$ & $46(25.0)$ & 0.008 \\
\hline & 15. All people with dementia can be registered as people with a disability & No & $96(41.6)$ & $28(59.6)$ & $68(37.0)$ & 0.005 \\
\hline & Average \% correct & & (44.7) & $(49.0)$ & (43.7) & \\
\hline \multirow[t]{5}{*}{$\begin{array}{l}\text { Symptoms and } \\
\text { diagnosis }\end{array}$} & $\begin{array}{l}\text { 8. When someone has intact memories of long-ago events, s/he doesn't get } \\
\text { dementia }\end{array}$ & No & $70(30.3)$ & $16(34.0)$ & $54(29.3)$ & 0.53 \\
\hline & 9. Dementia can change one's personal character & Yes & $218(94.4)$ & $44(93.6)$ & $174(94.6)$ & 0.73 \\
\hline & 10. Depression often accompanies dementia & Yes & $207(89.6)$ & $39(83.0)$ & $168(91.3)$ & 0.09 \\
\hline & 11. Dementia is diagnosed with a blood test & No & $123(53.2)$ & $30(63.8)$ & $93(50.5)$ & 0.10 \\
\hline & Average $\%$ correct & & (66.9) & (68.6) & (66.4) & \\
\hline \multirow{4}{*}{$\begin{array}{l}\text { Treatment and } \\
\text { prevention }\end{array}$} & 12. Dementia is not treatable & No & $54(23.4)$ & $15(31.9)$ & $39(21.2)$ & 0.12 \\
\hline & 13. Early treatment can delay dementia's progress & Yes & $211(91.3)$ & $40(85.1)$ & $171(92.9)$ & 0.09 \\
\hline & 14. Regular exercise can prevent dementia & Yes & $216(93.5)$ & $45(95.7)$ & $171(92.9)$ & 0.74 \\
\hline & Average $\%$ correct & & (69.4) & (70.9) & $(69.0)$ & \\
\hline Overall average & & & (61.6) & (64.1) & (60.9) & \\
\hline
\end{tabular}

Values are presented as number (\%).

${ }^{1}$ For the chi-square test or the Fisher exact test for correct answer frequency by gender.

and women (64.1 for men and 60.9 for women). Statistically significant score discrepancies were found between men and women for the following items: "If parents have dementia, their children will have it," "Dementia occurs more in men than in women," "1 out of 100 older adults has dementia," and "All people with dementia can be registered as people with a disability." The correct answer rate of male respondents was higher than that of their female counterparts for the items listed above, except for the item " 1 out of 100 older adults has dementia."

\section{Dementia Knowledge and Its Related Factors}

Table 3 shows the associations between study participants' knowledge about dementia and their characteristics. Dementia knowledge was significantly associated with age $(F=3.3$, $p=0.01)$, education $(F=17.2, p<0.001)$, health coverage ( $t=$ $2.1, p=0.04)$, source of living expenses $(F=3.4, p=0.04)$, and MMSE-DS $(z=-2.7, p=0.008)$.

People aged 85 and over scored only $8.0 \pm 1.7$ on average, which was significantly lower than the average score $(9.8 \pm$
1.9) of those aged 70 to 74 . Participants with no formal education scored lower $(8.8 \pm 1.9)$ than those with an elementary education (9.6 \pm 1.8 ) or a middle school and above education (10.9 \pm 2.0$)$. Type 1 Medical Aid beneficiaries showed a significantly higher level of knowledge $(9.9 \pm 2.7)$ than their type 2 counterparts (9.1 \pm 1.9 ). Regarding the source of living expenses, a statistically significant difference was found, as those who received support from their children showed lower levels of knowledge $(8.7 \pm 1.8)$, but the post-hoc analysis did not confirm this difference. The at-risk group of dementia according to the MMSE-DS showed the lowest average score of dementia knowledge (7.8 \pm 2.6$)$. In contrast, the low-risk group scored 9.3 \pm 1.9 .

\section{DISCUSSION}

It is well known that the prevalence of dementia is increasing globally. Many countries, including Korea, have begun to focus attention on how to deal with the burden of this disease. The knowledge level of rural older adults living alone about 
Table 3. Participants' dementia knowledge by their characteristics $(n=231)$

\begin{tabular}{|c|c|c|c|}
\hline Characteristics & Mean \pm SD & $\begin{array}{l}t \text { or } F \text { or } z \\
\text { ( } p \text {-value) }\end{array}$ & Scheffé \\
\hline \multicolumn{4}{|l|}{ Gender } \\
\hline Men & $9.6 \pm 2.2$ & $1.4(0.20)$ & \\
\hline Women & $9.1 \pm 2.0$ & & \\
\hline \multicolumn{4}{|l|}{ Age (y) } \\
\hline $65-69^{a}$ & $9.3 \pm 2.3$ & $3.3(0.01)$ & $e<b$ \\
\hline $70-74^{b}$ & $9.8 \pm 1.9$ & & \\
\hline $75-79^{c}$ & $9.2 \pm 1.9$ & & \\
\hline $80-84^{d}$ & $9.3 \pm 2.3$ & & \\
\hline$\geq 85^{\mathrm{e}}$ & $8.0 \pm 1.7$ & & \\
\hline \multicolumn{4}{|l|}{ Education } \\
\hline None ${ }^{a}$ & $8.8 \pm 1.9$ & $17.2(<0.001)$ & $a<b<c$ \\
\hline Elementary ${ }^{b}$ & $9.6 \pm 1.8$ & & \\
\hline$\geq$ Middle school $^{c}$ & $10.9 \pm 2.0$ & & \\
\hline \multicolumn{4}{|c|}{ Health coverage (Medical Aid) } \\
\hline Type 1 & $9.9 \pm 2.7$ & $2.1(0.04)$ & \\
\hline Type 2 & $9.1 \pm 1.9$ & & \\
\hline \multicolumn{4}{|l|}{ Source of living expenses } \\
\hline By working & $9.6 \pm 1.6$ & $3.4(0.04)$ & \\
\hline Public assistance & $9.6 \pm 2.7$ & & \\
\hline Support from children & $8.7 \pm 1.8$ & & \\
\hline Others & $9.2 \pm 2.2$ & & \\
\hline \multicolumn{4}{|l|}{ No. of chronic diseases } \\
\hline 0 & $8.8 \pm 2.9$ & $0.6(0.60)$ & \\
\hline 1 & $9.4 \pm 2.3$ & & \\
\hline 2 & $9.3 \pm 1.7$ & & \\
\hline$\geq 3$ & $9.1 \pm 1.7$ & & \\
\hline \multicolumn{4}{|l|}{ Self-rated health } \\
\hline Very good & $9.2 \pm 2.2$ & $0.8(0.50)$ & \\
\hline Good & $9.0 \pm 2.9$ & & \\
\hline Fair & $9.5 \pm 1.8$ & & \\
\hline Bad & $9.0 \pm 1.8$ & & \\
\hline Very bad & $8.9 \pm 1.3$ & & \\
\hline \multicolumn{4}{|l|}{ Drinks alcohol } \\
\hline No & $9.1 \pm 2.0$ & $1.7(0.10)$ & \\
\hline Yes & $9.6 \pm 1.9$ & & \\
\hline \multicolumn{4}{|l|}{ Dementia risk } \\
\hline Low-risk & $9.3 \pm 1.9$ & $-2.7(0.008)$ & \\
\hline At-risk & $7.8 \pm 2.6$ & & \\
\hline
\end{tabular}

$\mathrm{SD}$, standard deviation.

dementia, which is key for early detection and successful treatment, was assessed in this study.

The study participants showed relatively low levels of dementia knowledge (correct answer rate, 61.6\%), confirming the results of previous studies of rural older adults [25]. Compared to the rural study participants, those in urban areas have shown higher correct answer rates $(64.5,66.7 \%)$ [26,27]. Although there were high correct answer rates within 4 categories, those of the study participants ranged from 44.7 to $69.4 \%$, while those of urban older adults ranged from 60.6 to $66.1 \%$ [26]. Of particular note, roughly half of the study participants incorrectly believed that dementia is a part of aging. In other studies, only $23.4 \%$ of Korean urban residents [26] and $7.3 \%$ of Japanese residents believed this [28].

This study also underscores generational differences, as well as rural/urban differences, in knowledge about dementia. Other studies have found that citizens in their 20 s had an average of $85.8 \%$ correct answers [27], and a group of adults had $75.0 \%$ [26]. These proportions were all higher than the rate of $61.6 \%$ among the participants in this study, who were in their mid-70s on average. This suggests that there is an urgent need to provide information on dementia to rural older adults living alone.

Participants' lowest score was on the item "Dementia is not treatable," which only $23.4 \%$ answered correctly. This proportion was lower than the $48.0 \%$ of Korean urban older residents [26] and 37.8\% of Japanese community residents [28] who answered this item correctly. This negative belief was also reported in a US panel study [29], which highlighted the possibility that this belief could hinder older adults from actively seeking dementia treatment. However, in a 1999 national survey, only $5.7 \%$ of Korean citizens answered this correctly [30], and this improvement could be interpreted as the result of national outreach for dementia management.

Among the items regarding symptoms of dementia, participants showed relatively high levels of knowledge that dementia can change one's character and can be accompanied by depression. However, only about $30.0 \%$ of the study participants were aware that long-term memory function remains intact in the early stages of dementia. This item also had a low correct answer rate among urban older adults (34.2\%) [27]. Since study participants showed a high level of knowledge about the importance of early detection and regular exercise for preventing dementia, education about patterns of memory loss and about treatment could encourage them to actively seek dementia treatment. Educational outreach programs would be beneficial for improving the early detection and treatment of dementia.

The overall and categorical average correct answer rates of 
male respondents were higher than those of their female counterparts. Although statistically significant differences between men and women were found for only 4 items, the correct answer rate was higher for men than for women 9 of the 15 items. Because there was no significant difference in age between men and women, gender discrepancies in the correct answer rates can be attributed to the gender gap in education. In the past, Korean women had no choice but to sacrifice themselves for their brothers' education, often against their will. In fact, there was a significant difference in educational level between the men and women study participants (data not shown). Previous studies have also reported that education was significantly associated with dementia knowledge $[26,29,30]$.

Old age and low levels of education have been reported to be significant factors related to knowledge levels about illnesses, including dementia [26-28]. The results of the current study confirmed this. Participants aged 85 years and older showed the lowest level of dementia knowledge. We further analyzed the mean MMSE-DS scores by age group, and the group aged 85 and older showed the lowest mean score on the MMSE-DS (20.9 \pm 4.3$)$. It is possible that the deterioration of cognitive function with aging hindered older participants from obtaining new knowledge.

All of the participants received Medical Aid from the government, which is divided into types 1 and 2 assistance based on physical function and personal assets. Interestingly, participants who belonged to type 1 had more knowledge about dementia than their type 2 counterparts. Participants in the type 1 group had more free time than their type 2 counterparts because most of them did not work for their living (data not shown). Therefore, they tended to get help from and communicate with their community health practitioners, and were more likely to receive information on dementia. Regarding the source of living expenses, however, further investigation is needed to determine why working participants were more knowledgeable about dementia.

Health care providers in rural communities need to pay more attention to older adults living alone. Based on the MMSE-DS, approximately $6.9 \%$ of the study participants needed further evaluation for dementia. More than half of the participants experienced mild cognitive impairment; this proportion is markedly higher than the $27.8 \%$ reported in a national survey [2] and the $24.3 \%$ reported in urban community settings [31]. Other studies have also found rates of mild cogni- tive impairment of 5.0-36.7\% among older community residents [32]. In addition, all of the participants lived alone, which is known to be an aggravator of cognitive function deterioration [15-18].

This study has some limitations. First, the study participants_-rural older adults living alone-were not compared to their urban/younger counterparts and/or older adults living with others, and recruiting such counterparts in a future study will provide a more complete picture. Second, investigating their knowledge about other diseases, such as stroke, would have provided an opportunity to identify significant factors related to dementia knowledge in particular. Third, we did not employ a probability sampling technique, which might hamper the external validity of the study. For example, all of the participants were incidentally Medical Aid beneficiaries, although rural older adults living alone are known to be poorer than their younger and/or urban counterparts and the general population. Fourth, some variables associated with dementia knowledge were unfortunately not included in the study. For example, although a previous study [33] identified depression as a factor related to dementia knowledge, this study failed to measure the depression level of the study participants. The community health practitioners told the authors that there was little variation in the depression level among rural older adults, but a measure of depression should have been employed to confirm their impressions. Lastly, we did not provide results from multiple regression analysis. We conducted multiple linear regression analyses, but we were not sure that the results of the study would be robust because of the small sample size and selection bias. Instead, we aimed to focus on the level of dementia knowledge among older adults living alone in a rural area.

Despite the limitations mentioned above, this study showed that the level of dementia knowledge among Korean rural older adults living alone was relatively low. It was lower than among younger generations and urban older adults. Participants' misconceptions about symptoms and treatment could hinder them from seeking early treatment. The results of this study suggest the need for active outreach and health care delivery for rural older adults living alone in Korea.

\section{CONFLICT OF INTEREST}

The authors have no conflicts of interest associated with the material presented in this paper. 


\section{ORCID}

Mi Sook Kim http://orcid.org/0000-0002-3509-9499

Dong-Soo Shin https://orcid.org/0000-0002-5289-3571

Yong-jun Choi https://orcid.org/0000-0002-1622-3175

\section{REFERENCES}

1. Prince M, Wimo A, Guerchet M, Ali MG, Wu YT, Prina M. World Alzheimer report 2015: the global impact of dementia-an analysis of prevalence, incidence, cost and trends [cited 2018 Jun 19]. Available from: https://www.alz.co.uk/research/WorldAlzheimerReport2015.pdf.

2. Kim K, Gwak K, Kim B, Kim S, Kim S, Kim J, et al. Nationwide survey on the dementia epidemiology of Korea. Seongnam: Seoul National University Bundang Hospital; 2012, p. 83-151 (Korean).

3. Gauthier S, Reisberg B, Zaudig M, Petersen RC, Ritchie K, Broich K, et al. Mild cognitive impairment. Lancet 2006;367(9518): 1262-1270.

4. Suh GH, Knapp M, Kang CJ. The economic costs of dementia in Korea, 2002. Int J Geriatr Psychiatry 2006;21(8):722-728.

5. Kim S, Lee C. Status and improvement of the dementia management: program evaluation report 14-02. Seoul: National Assembly Budget Office; 2014, p. 34-35 (Korean).

6. Korean Statistical Information Service. Population and household [cited 2016 Apr 1]. Available from: http://kosis.kr/statisticsList/statisticsList_01List.jsp?vwcd=MT_ZTITLE\&parmTabld =M_01_01 (Korean).

7. Cho M, Park DS, Choi YW. Health status of the rural elderly and policy issue; report no. R699. Naju: Korea Rural Economic Institute; 2013, p. 15-37 (Korean).

8. Kim HO, Joung KH. Comparison of health lifestyle among elders according to residential area. J Korean Gerontol Nurs 2009;11(1):16-28 (Korean).

9. Montlahuc C, Soumaré A, Dufouil C, Berr C, Dartigues JF, Poncet $M$, et al. Self-rated health and risk of incident dementia: a community-based elderly cohort, the 3 C study. Neurology 2011;77(15):1457-1464.

10. St John P, Montgomery P. Does self-rated health predict dementia? J Geriatr Psychiatry Neurol 2013;26(1):41-50.

11. Baumgart M, Snyder HM, Carrillo MC, Fazio S, Kim H, Johns H. Summary of the evidence on modifiable risk factors for cognitive decline and dementia: a population-based perspective. Alzheimers Dement 2015;11(6):718-726.
12. Laurin D, Verreault R, Lindsay J, MacPherson K, Rockwood K. Physical activity and risk of cognitive impairment and dementia in elderly persons. Arch Neurol 2001;58(3):498-504.

13. Ahlskog JE, Geda YE, Graff-Radford NR, Petersen RC. Physical exercise as a preventive or disease-modifying treatment of dementia and brain aging. Mayo Clin Proc 2011;86(9):876884.

14. Choi J. The perception and attitude for rural older people [dissertation]. Chuncheon: Hallym University; 2011 (Korean).

15. Håkansson K, Rovio S, Helkala EL, Vilska AR, Winblad B, Soininen $\mathrm{H}$, et al. Association between mid-life marital status and cognitive function in later life: population based cohort study. BMJ 2009;339:b2462.

16. Mousavi-Nasab SM, Kormi-Nouri R, Sundström A, Nilsson LG. The effects of marital status on episodic and semantic memory in healthy middle-aged and old individuals. Scand J Psychol 2012;53(1):1-8.

17. van Gelder BM, Tijhuis M, Kalmijn S, Giampaoli S, Nissinen A, Kromhout D. Marital status and living situation during a 5-year period are associated with a subsequent 10-year cognitive decline in older men: the FINE Study. J Gerontol B Psychol Sci Soc Sci 2006;61(4):P213-P219.

18. Jung YM, Kim JH. Comparison of cognitive levels, nutritional status, depression in the elderly according to living situations. J Korean Acad Nurs 2004;34(3):495-503 (Korean).

19. Robinson L, Tang E, Taylor JP. Dementia: timely diagnosis and early intervention. BMJ 2015;350:h3029.

20. Yun MJ, Sohn AR. Factors that affect health promotion behavior for prevention of dementia. Korea Sports Res 2004;15(6): 811-820 (Korean).

21. Kim TH, Jhoo JH, Park JH, Kim JL, Ryu SH, Moon SW, et al. Korean version of Mini Mental Status Examination for Dementia Screening and its' short form. Psychiatry Investig 2010;7(2): 102-108.

22. Han JW, Kim TH, Jhoo JH, Park JH, Kim JL, Ryu SH, et al. A normative study of the Mini-Mental State Examination for Dementia Screening (MMSE-DS) and its short form (SMMSE-DS) in the Korean elderly. J Korean Geriatr Psychiatry 2010;14(1): 27-37 (Korean).

23. Folstein MF, Folstein SE, McHugh PR. "Mini-mental state". A practical method for grading the cognitive state of patients for the clinician. J Psychiatr Res 1975;12(3):189-198.

24. Ku BD, Kim SG, Lee JY, Park KH, Shin JH, Kim KK, et al. Clinical practice guideline for dementia by clinical research center for dementia of South Korea. J Korean Med Assoc 2011;54(8):861- 


\section{5 (Korean).}

25. Cho M, Kim K, Kim M, Kim M, Kim B, Kim S, et al. Nationwide study on the prevalence of dementia in Korean elders. Seoul: Ministry of Health, Welfare and Family Affairs; 2008, p. 146-157 (Korean).

26. Seo HJ, Lee DY, Sung MR. Public knowledge about dementia in South Korea: a community-based cross-sectional survey. Int Psychogeriatr 2015;27(3):463-469.

27. Sung MR. A survey on the awareness of dementia and care needs for dementia programs. Gwangmyeong: Gwangmyeong City; 2014, p. 30-36 (Korean).

28. Arai Y, Arai A, Zarit SH. What do we know about dementia?: A survey on knowledge about dementia in the general public of Japan. Int J Geriatr Psychiatry 2008;23(4):433-438.

29. Roberts JS, McLaughlin SJ, Connell CM. Public beliefs and knowledge about risk and protective factors for Alzheimer's disease. Alzheimers Dement 2014;10(5 Suppl):S381-S389.

30. Cho HO. A study on public's knowledge of and attitude towards dementia [dissertation]. Seoul: Hanyang University; 1999 (Korean).

31. So H, Ju K, Jung M, Kim H. Cognitive function of the urban elderly. Korean J Rehabil Nurs 2004;7(2):179-187 (Korean).

32. Sachdev PS, Lipnicki DM, Kochan NA, Crawford JD, Thalamuthu $A$, Andrews $G$, et al. The prevalence of mild cognitive impairment in diverse geographical and ethnocultural regions: the COSMIC collaboration. PLoS One 2015;10(11): e0142388.

33. Lee JY, Park S, Kim KW, Kwon JE, Park JH, Kim MD, et al. Differences in knowledge of dementia among older adults with normal cognition, mild cognitive impairment, and dementia: a representative nationwide sample of Korean elders. Arch Gerontol Geriatr 2016;66:82-88. 